\title{
Preparation of the Natural Zeolite Based Catalyst for Hydrocracking Process of Petroleum Derived Atmospheric Residue
}

\author{
Tserendorj Tugsuu $^{1}$, Yoshikazu Sugimoto ${ }^{2}$, Byambajav Enkhsaruul ${ }^{3}$ \\ ${ }^{1}$ Department of Chemical and Biological Engineering, School of Engineering and Applied Science, National University of \\ Mongolia (NUM), Ulaanbaatar, Mongolia \\ ${ }^{2}$ Energy Technology Research Institute, Advanced Industrial Science and Technology (AIST), Tsukuba, Japan \\ ${ }^{3}$ Department of Chemistry, School of Art and Science, National University of Mongolia (NUM), Ulaanbaatar, Mongolia \\ Email: tserendorj.tugsuu@yahoo.com
}

How to cite this paper: Tugsuu, Ts., Sugimoto, Y. and Enkhsaruul, B. (2017) Preparation of the Natural Zeolite Based Catalyst for Hydrocracking Process of Petroleum Derived Atmospheric Residue. Journal of Materials Science and Chemical Engineering, 5, 14-22.

https://doi.org/10.4236/msce.2017.511002

Received: September 1, 2017

Accepted: November 10, 2017

Published: November 13, 2017

Copyright (๑) 2017 by authors and Scientific Research Publishing Inc.

This work is licensed under the Creative Commons Attribution International License (CC BY 4.0).

http://creativecommons.org/licenses/by/4.0/

(c) (i) Open Access

\begin{abstract}
This research focused on preparation catalysts by natural zeolite for hydrocracking and to compare their catalytic reactivity with commercial catalyst. Clinoptilolite type natural zeolite of Tsagaantsav and paraffinic atmospheric residue of Tamsagbulag crude oil were used in this research. The Ni or Fe ion was loaded into the zeolite sample which was enriched and calcined previously, by ion exchange method. It is determined by X-ray diffraction analysis that structure of natural zeolite was not broken down during metal loading. The conversion of feedstock in hydrocracking, in with modified zeolite was used, was $22.5 \%$ higher than none catalytic process and $8.9 \%$ higher than commercial catalyst. It is proved that both of modified zeolite catalysts worked effectively as a catalyst in hydrocracking of atmospheric residue. Even so the contents of sulfur in middle and heavy fraction were $490-615 \mathrm{ppm}$, after hydrocracking with $\mathrm{Ni} /$ zeolite, Fe/zeolite catalysts. This result showed that the $\mathrm{Ni} /$ zeolite, Fe/zeolite catalysts were inactive at hydrodesulfurization, because the contents of sulfur in middle and heavy fraction were 370 - 478 ppmafter hydrocracking without catalyst. Process for sulfur removal is needed after hydrocracking with $\mathrm{Ni} /$ zeolite orFe/zeolite catalyst.
\end{abstract}

\section{Keywords}

Zeolite Catalyst, Hydrocracking, Catalytic Reactivity, Hydrodesulfurization

\section{Introduction}

The most important advance in cracking technology in the last seven decades 
where zeolite catalysts develop has been known. There are 34 known natural zeolites, and about 100 zeolites have been synthesized [1]. Currently more than ten fields of natural zeolite in Mongolian territory have been disclosed and all the resource has been estimated to be 179.1 million ton [2]. Natural zeolite of Tsagaantsav and crude oil of Tamsagbulag had been studied for several years [3] [4]. However, there is no research to prepare a cracking catalyst by natural zeolite for refining process of petroleum in Mongolia. In this study, we have performed a modification of natural zeolite for cracking catalyst and to compare its catalytic reactivity on atmospheric residue of crude oil.

However, initially the cracking process was without catalysts, but the catalyst develop rapidly after using catalyst for cracking process and the using of $2-3$ functional catalyst for the petroleum refinery [5]. To improve catalytic reactivity of natural zeolite, modifying and synthesis methods were used [6].

\section{Experimental}

\subsection{Materials}

In this research we used the natural zeolite of Tsagaantsav to prepare cracking catalyst and the commercial catalyst, which was utilized in Japanese refinery to compare their catalytic reactivity. Also the atmospheric residue of Tamsagbulag crude oil was used as a raw material of hydrocracking.

\subsection{Catalyst Preparation}

The $\mathrm{Ni}, \mathrm{Fe}$ ions were loaded into the pore structure of natural zeolite, which was enriched and activated previously, by ion exchange method, which is shown in Figure 1.

We prepared a zeolite sample of $1.0 \mathrm{~mm}$ in diameter using winnowing fan, after the natural zeolite was swilled out by distilled water many times and cleaned from clay soils. The thermal activation had been made that, half of swilled zeolite calcined at $350^{\circ} \mathrm{C}$ for 3 hours [7]. The metal ions in pore of zeolite crystal had been displaced by ammonium ion via adding $0.25 \mathrm{~mol} / 1 \mathrm{NH}_{4} \mathrm{Cl}$ solution to the samples of swilled zeolite and activated zeolite. Thus, the zeolite ion exchange capacity was calculated from the variance concentration of ammonium ions. It was modified $\mathrm{Ni} /$ zeolite and $\mathrm{Fe} /$ zeolite catalyst through the ammonia form of exchange ion in zeolite crystalline valley, ion-exchanged into $\mathrm{Ni}$ and $\mathrm{Fe}$ form.To do this, at first the $20 \%$ solution of $\mathrm{NiCl}_{2}$ and $\mathrm{FeCl}_{3}$ was prepared.Then a $5 \mathrm{~g}$ ammonized zeolite was put in a flask, prepare the mixture for the zeolite and salt ratio of $1: 5$, and heat and stir it with a reflux condenser at $80^{\circ} \mathrm{C}$ for 3 hours. Finally modified $\mathrm{Ni} /$ zeolite and $\mathrm{Fe} /$ zeolite catalyst via the filtered zeolite was disinfected until no chlorine ion and burned at $400^{\circ} \mathrm{C}$ for 4 hours.

\subsection{Hydrocracking Test}

The atmospheric residue of Tamsagbulag crude oil (TBAR) was hydrocracked at $450^{\circ} \mathrm{C}$ temperature using a fixed bed reactor that was inserted into an electric 


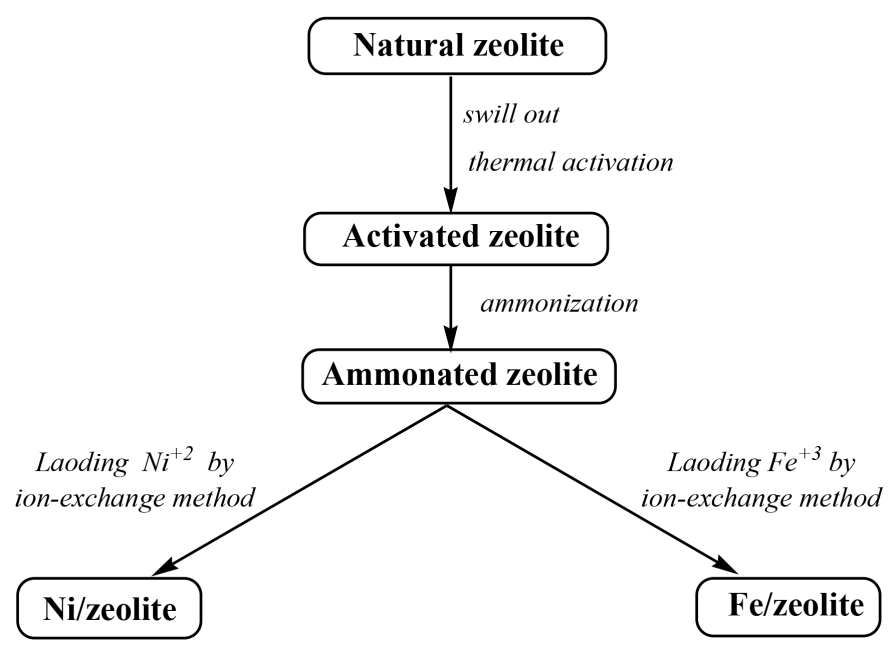

Figure 1. General scheme of method to prepare zeolite catalyst.

furnace with vertically sharking type. About $4 \mathrm{~g}$ of atmospheric residue with 200 mg of prepared catalyst were charged into the reactor. The reactor was pressurized by hydrogen gas up to $10 \mathrm{MPa}$ at ambient temperature, and then was heated to the prescribed temperature. Reaction temperature was maintained for 2 hours for every run [8].

\subsection{Analysis}

\subsubsection{XRD Analysis for Modified Zeolite Catalyst}

The crystalline structure of the modified zeolite and the bi-functions commercial catalyst was determined using the D500 X-ray diffractometer. The measurements at the $2 \theta$ angle of $10^{\circ}$ to $60^{\circ}$ had been carried out to measure the accuracy of the 0.01 , every 3 seconds. Using copper metal as a source of X-rays.

\subsubsection{Determine the Amount of Metal in the Catalyst}

A ULVAC PHI 5600 type X-ray photoelectron spectroscopy (XPS) was used to measure the amount of metal in the zeolite catalysts. The Al- $\mathrm{K}_{\alpha}$ with $200 \mathrm{~W}$ voltage was used as a source of X-rays. Calculated by $1 \mathrm{~s}$ peak intensity at $285.0 \mathrm{eV}$ of carbon and calculated by modifying variance of observed X-ray spectral.

\subsubsection{Hydrocracking Product Analysis}

After the reaction, gaseous products were subjected to Gas chromatography coupled with thermal conductivity detector (GC-TCD; Agilent, 6890) to estimate its composition. Then, contents of methane, ethane and propane gases were calculated using a calibration of standard gas samples. Initially, atmospheric residue was separated using a distillation method to examine quantitatively its fractional composition. The distillation curve of the liquid product was examined using a GC-FID system (Agilent, model 6890 GC) that was equipped with a fused silica column $5 \mathrm{~m}$ long [9]. At first, the toluene insoluble fraction (TIF) was extracted from hydrocracking products. The toluene soluble fraction (TS) was recovered after solvent evaporation, and was then divided into four sub 
fractions by a distillation method: light fraction (LF), middle fraction (MF), heavy fraction (HF) and bottom. The separated distinct fractions were weighed to check a material balance including the content of gaseous products [10].

\section{Results and Discussion}

\subsection{Catalyst Preparation and Analysis}

The $\mathrm{Ni}$ or $\mathrm{Fe}$ ions was loaded into the zeolite sample after enrichment and activation of natural zeolite by ion exchange method. The quality of adsorption or the ion exchange capacity of natural zeolite was improved from $0.21 \mathrm{mmol} / \mathrm{g}$ to $0.41 \mathrm{mmol} / \mathrm{g}$ after swill out and thermal activation of natural zeolite.The modified $\mathrm{Ni}$ /zeolite, Fe/zeolite catalysts were identified, that the clinoptilolite type zeolite by database in D500 instrument. Results of ammonification for activated natural zeolite shows that ion exchange capacity of the zeolite was 0.41 $\mathrm{mmol} / \mathrm{g}$. It means that metal $\mathrm{Ni}$ or $\mathrm{Fe}$ ions can be loaded $0.41 \mathrm{mmol}$ into $1 \mathrm{~g}$ of zeolite by ion exchange method. In Figure 2, X-ray diffraction analysis of the modified zeolite catalysts is confirmed that, structure of the natural zeolite was
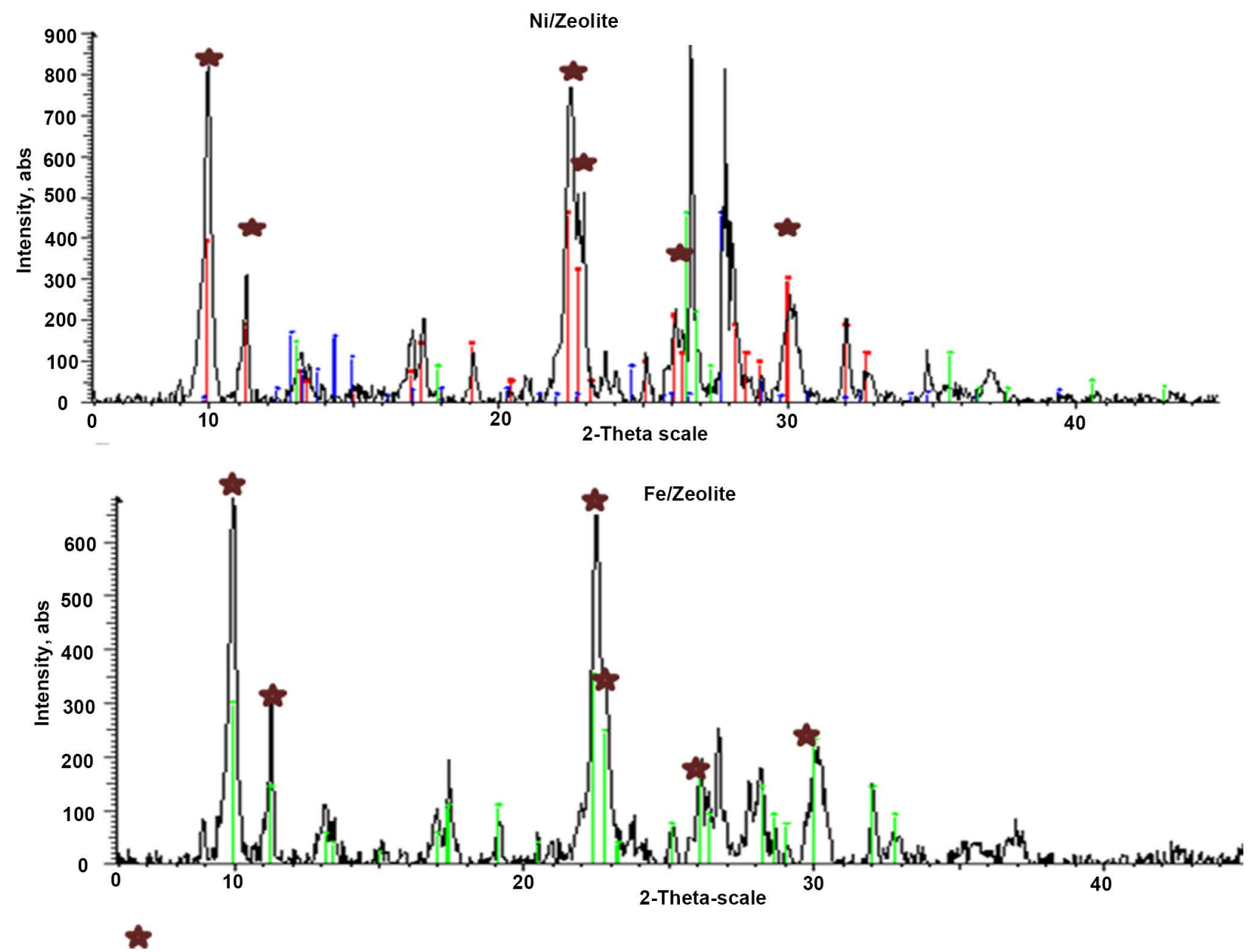

Figure 2. X-ray diffraction pattern of the $\mathrm{Ni}$ and Fe ion exchanged zeolite. 
not broken down during the metal loading and that, the raw material is Clinoptilolite type natural zeolite.

It makes clear disclosed the crystal structure of zeolite at the interval $10-20$ and $20-40$ of $2 \theta$. Also there is no large and agglomerated $(>5 \mathrm{~nm})$ metal species in the framework of zeolite. In other words, $\mathrm{Ni}$ and Fe metals are too small to be detected by X-ray analysis. It means that metal species loaded into the zeolite are distributed finely during ion exchange.

The researchers assigned that the thermal stability of Tsagaantsav zeolite is $950^{\circ} \mathrm{C}$ of temperature [2]. Therefore Ni/zeolite, Fe/zeolite catalysts were possible to use in hydrocracking process, which is carried out at $450^{\circ} \mathrm{C}-500^{\circ} \mathrm{C}$ of temperature.

Structure of commercial catalyst exhibited almost amorphous by the X-ray diffraction analysis in Figure 3. It showed that the metal content in commercial catalyst was lower than ion exchanged zeolite.

The chemical element's content in activated zeolite and ion exchanged zeolites had been determined by X-ray photoelectron spectroscopy (XPS) analysis. The results of analysis are shown in Table 1.

TheSi/Alatomic ratio in modified zeolites was around 4.1. It was nearby to data of the clinoptilolite type, which is 4.2. The results of analysis demonstrated that the $\mathrm{Ca}$ and $\mathrm{K}$ ions in the Tsagaantsav's zeolite were exchange by $\mathrm{Ni}$ and $\mathrm{Fe}$ ions because the weight contents $\mathrm{Ni}$ and $\mathrm{Fe}$ were $7.18 \%$ and $5.14 \%$ in the $\mathrm{Ni} /$ zeolite, Fe/zeolite.

\subsection{Hydrocracking Test and Product Analysis}

Table 2 shows the product distribution after hydrocracking at $450^{\circ} \mathrm{C}$ for 2 hours under hydrogen pressure of $10 \mathrm{MPa}$. As a result of experiments, which used modified zeolite catalysts, the conversion of feedstock, yields of light and middle fraction were higher, the amounts of heavy fraction, bottom and grown up coke lower, than the experiment which used commercial catalyst.

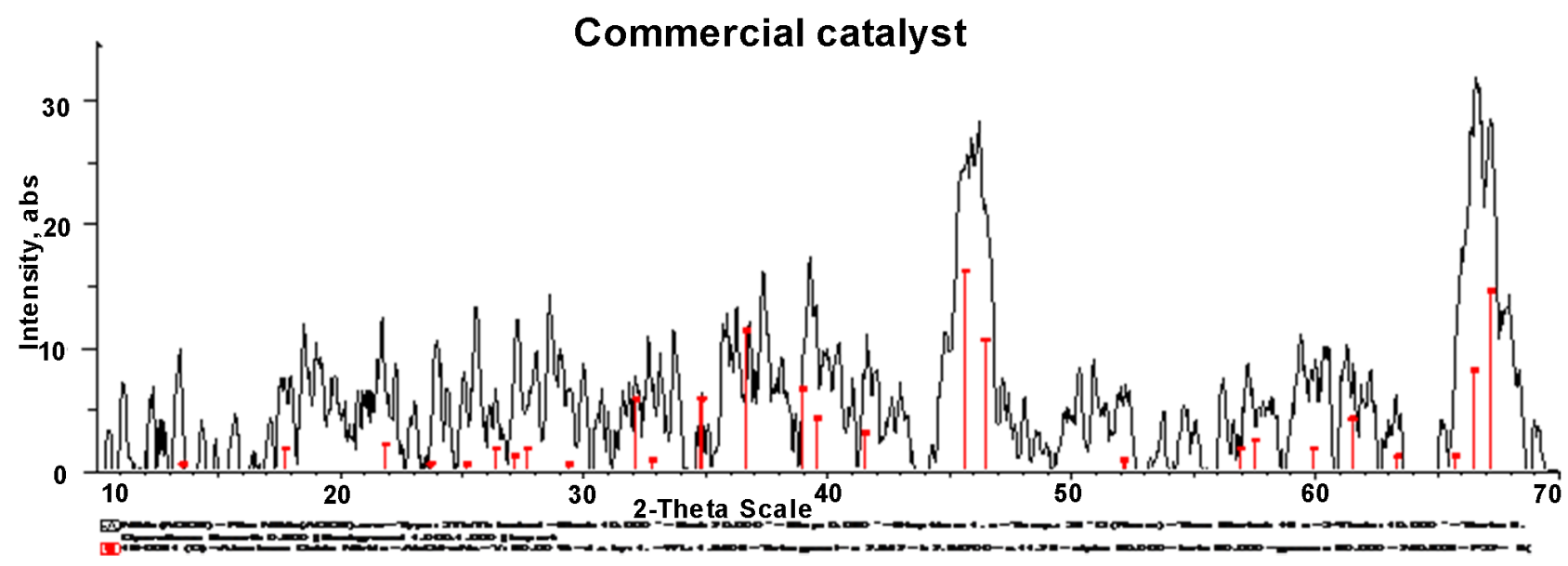

Figure 3. X-ray diffraction pattern of the commercial catalyst. 
Table 1. The result of XPS chemical analysisof Ni/zeolite, Fe/zeolite and activated zeolite.

\begin{tabular}{|c|c|c|c|c|c|c|}
\hline \multirow[b]{2}{*}{ Elements } & \multicolumn{2}{|c|}{ Activated zeolite } & \multicolumn{2}{|c|}{$\mathrm{Ni} /$ zeolite } & \multicolumn{2}{|c|}{$\mathrm{Fe} /$ zeolite } \\
\hline & $\begin{array}{c}\text { Atomic } \\
\text { content, } \%\end{array}$ & $\begin{array}{c}\text { Weight } \\
\text { content, } \%\end{array}$ & $\begin{array}{c}\text { Atomic } \\
\text { content, \% }\end{array}$ & $\begin{array}{c}\text { Weight } \\
\text { content, \% }\end{array}$ & $\begin{array}{c}\text { Atomic } \\
\text { content, \% }\end{array}$ & $\begin{array}{c}\text { Weight } \\
\text { content, \% }\end{array}$ \\
\hline $\mathrm{Si}$ & 25.4 & 35.08 & 25.8 & 34.55 & 26.2 & 35.59 \\
\hline $\mathrm{Al}$ & 6.1 & 8.12 & 6.2 & 8.04 & 6.4 & 8.26 \\
\hline $\mathrm{O}$ & 63 & 49.59 & 64.3 & 49.02 & 64.9 & 50.31 \\
\hline $\mathrm{Na}$ & 4.3 & 4.87 & 1.1 & 1.21 & 0.6 & 0.7 \\
\hline $\mathrm{K}$ & 0.7 & 1.35 & - & - & - & - \\
\hline $\mathrm{Ca}$ & 0.5 & 0.99 & - & & - & - \\
\hline $\mathrm{Ni}$ & - & - & 2.6 & 7.18 & - & - \\
\hline $\mathrm{Fe}$ & - & - & - & - & 1.9 & 5.14 \\
\hline $\mathrm{Si} / \mathrm{Al}$ & 4.16 & & 4.16 & & 4.09 & \\
\hline
\end{tabular}

Table 2. The products distribution after catalytic hydrocracking of atmospheric residue.

\begin{tabular}{cccccccccc}
\hline \multirow{2}{*}{ Catalyst } & Conversion, & \multirow{2}{*}{$\begin{array}{c}\text { Hydrogen } \\
\text { consumption, } \%\end{array}$} & \multicolumn{5}{c}{ Product distribution } \\
\cline { 6 - 9 } & & & $\mathrm{C}_{1}-\mathrm{C}_{3}$ Gas & LF & MF & HF & Bottom & Coke \\
\hline Commercial & 56.5 & 0.5 & 3.7 & 29.4 & 22.0 & 38.0 & 5.5 & 2.2 \\
Ni/zeolite & 65.4 & 0.4 & 3.3 & 36.6 & 24.6 & 27.3 & 7.4 & 1.2 \\
Fe/zeolite & 62.1 & 0.2 & 3.6 & 33.3 & 23.8 & 33.2 & 4.7 & 1.6 \\
None & 42.9 & 0.1 & 3.1 & 22.9 & 14.0 & 35.3 & 21.8 & 3.0 \\
\hline
\end{tabular}

Especially the conversion of feedstock was $50 \%$ higher than none catalytic process and $15.7 \%$ higher than commercial catalyst. It is proved that both of modified zeolite catalysts worked effectively as a catalyst in hydrocracking of atmospheric residue.

The contents of subfractions and n-paraffin $\left(\mathrm{C}_{9}-\mathrm{C}_{38}\right)$ on some products of hydrocracking by GC-FID analysis were shown in Table 3 . The content of subfraction $<254^{\circ} \mathrm{C}$ was lowest and the content of subfractions $<344^{\circ} \mathrm{C}$ and $<496^{\circ} \mathrm{C}$ were highest on middle and heavy distillates of product after hydrocracking process, which used the $\mathrm{Ni}$ ion exchanged zeolite catalyst. The contents of $\mathrm{n}$-paraffins on middle and heavy distillate, were highest, when used commercial catalyst. It is related the amount of hydrogen for conversion was highest at hydrocracking reaction. In other words the paraffin is cracked to give two smaller paraffins undergo the hydrogen pressure. Also the n-paraffins are expended to the reactions of isomerization, formation of olefin, naphthen and aromatics via surface carbonium-ion intermediates at acidic surface of zeolite catalysts.

The content of sulfur in MF and HF after hydrocracking was determined to evaluate activity of hydrodesulfurization for the commercial and zeolite catalysts. The contents of sulfur in middle and heavy fraction are shown in Figure 4.

As the result, the contents of sulfur in middle and heavy fraction were reduced to $19 \mathrm{ppm}, 22 \mathrm{ppm}$ after hydrocracking with commercial catalyst, because not 
Table 3. The contents of subfractions and $n$-paraffins in hydrocracking products [wt\%].

\begin{tabular}{ccccc}
\hline Catalyst & Commercial & Ni/zeolite & Fe/zeolite & none \\
\hline Subfractions & & Middle fraction & & \\
\hline$<151^{\circ} \mathrm{C}$ & - & - & - & - \\
$<254^{\circ} \mathrm{C}$ & 42.8 & 25.6 & 35.3 & 30.2 \\
$<344^{\circ} \mathrm{C}$ & 53.9 & 66.3 & 59.0 & 60.5 \\
$>344^{\circ} \mathrm{C}$ & 3.3 & 8.1 & 5.7 & 9.3 \\
n.paraffins & 46.3 & 40.6 & 41.5 & 38.7 \\
\hline Subfractions & & Heavy fraction & & \\
\hline$<254^{\circ} \mathrm{C}$ & 0.2 & - & - & 0.7 \\
$<344^{\circ} \mathrm{C}$ & 34.3 & 16.0 & 16.0 & 23.0 \\
$<496^{\circ} \mathrm{C}$ & 63.4 & 80.0 & 76.0 & 73.2 \\
$>496^{\circ} \mathrm{C}$ & 2.1 & 4.0 & 8.0 & 3.1 \\
n.paraffins & 41.1 & 32.1 & 32.0 & 39.3 \\
\hline
\end{tabular}

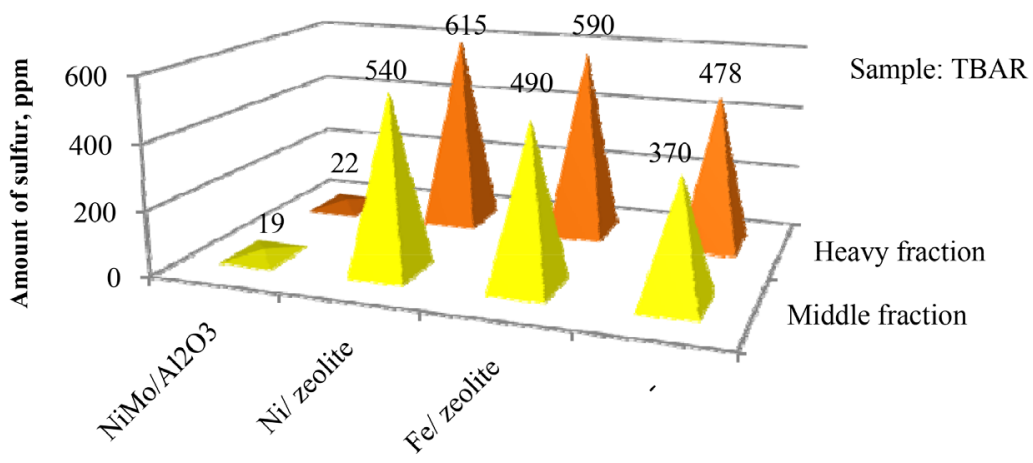

\section{Catalyst}

Figure 4. Influence of catalyst on content of sulfur in middle and heavy fraction after HC.

only cracking reaction but also hydrodesulfurization was being hold excellent during the process. Even so the contents of sulfur in middle and heavy fraction were 490 - 615 ppm after hydrocracking with $\mathrm{Ni} /$ zeolite, Fe/zeolite catalysts. This result was evidenced the $\mathrm{Ni}$ /zeolite, Fe/zeolite catalysts were inactive at hydrodesulfurization, because the contents of sulfur in middle and heavy fraction were 370 - 478 ppm after hydrocracking without catalyst. Therefore there is a need for the sulfur removal process from products after hydrocracking with Ni/zeolite or $\mathrm{Fe} /$ zeolite catalysts.

\section{Conclusions}

Prepared $\mathrm{Ni}$ /zeolite and Fe/zeolite catalysts were used in the hydrocracking process of TBAR and their catalytic reactivityof cracking and hydrodesulfurization reaction were compared with the bi-function commercial catalyst and none 
catalyst process.

In the none catalyst process, the conversion was minimum (42.9 wt\%), the amount of residue was the highest (21.8 wt\%). Therefore, it is necessary to use active catalysts in the hydrocracking process. The research showed that, prepared zeolite catalysts were more active in hydrocracking reaction than commercial catalyst and none catalysis process.

It is possible to use $\mathrm{Ni}$ /zeolite and $\mathrm{Fe} /$ zeolite as a catalyst in the hydrocracking process $\left(450^{\circ} \mathrm{C}-500^{\circ} \mathrm{C}\right)$ because the heat resistance of Tsagaantsav's zeolite is $950^{\circ} \mathrm{C}$.

$\mathrm{Ni}$ /zeolite and $\mathrm{Fe} /$ zeolite catalysts were inactive in hydrodesulfurization reaction. The desulfurization process is required after hydrocracking with prepared zeolite catalysts.

\section{Acknowledgements}

This material is based on research grants supported by Higher education reforming project in Mongolia. We would like to express gratitude to senior researcher Yoshikazu Sugimoto for providing us a great opportunity to do some experiments of this research.

\section{References}

[1] Bruce, C.G., James, R.K. and Schuit, A.G. (1979) Chemisrty of Catalytic Processes. McGraw Hill, New York.

[2] Oyuntsetseg, J. (2005) Physical and Chemical Properties of Natural Zeolite of Tsagaantsav Field. Ph.D. Dissertation, National University of Mongolia, Ulaanbaatar.

[3] Zolzaya, T.S., Davaabal, B. and Minjigmaa, A. (2011) The Mechanochemical Activation Study of Tsagaantsav Zeolite. Mongolian Journal of Chemistry, 12, 98-101. http://www.mongoliajol.info/index.php/MJC/article/view/181/179

[4] Oyun J. (2009) The Investigation on Preparation of Nano-Sized Raw Medicinal Material from the Natural Spar. Proceedings of the Mongolian Academy of Science, 49, 90-100. http://www.mongoliajol.info/index.php/PMAS/article/view/52/52

[5] Yoshikazu, S., Aihara, Y., Matsumura, A., Ohi, A., Sato, S., Saito, I. and Yui, S. (2006) Processing of Middle East crude with Canadian oil sands bitumen-derived synthetic crude oil. Journal of the Japan Petroleum Institute, 49, 1-12. https://www.jstage.jst.go.jp/article/jpi/49/1/49_1_1/_pdf

[6] Masato, K., Yasunori, K., Kunio, U. and Yoshikazu, S. (2005) Catalytic Hydrocracking of Petroleum Residue over Carbon-Supported Nickel-Molybdenum Sulfide. Energy and fuels, 19, 725-730.

[7] Enkhsaruul, B. (2004) Cracking of Oil-Derived Asphaltenes with Iron Catalysts on Solid Supports with Mesoporous Structure. Ph.D. Dissertation, Tohoku University, Sendai.

[8] Tugsuu, T., Sugimoto, Y., Enkhsaruul, B. and Monkhoobor, D. (2012) A Comparative Study on Catalytic Hydrocracking For Atmospheric Residue of Mongolian Tamsagbulag Crude Oil and Other Crude Oils. Advances in Chemical Engineering and Science, 2, 402-407. http://file.scirp.org/pdf/ACES20120300011_85910754.pdf

[9] Sugimoto, Y., Horie, Y., Saotome, Y., Tugsuu, T.S. and Enkhsaruul, B. (2012) Properties, Chemical Compositions and Hydrotreatment Reactivities of Mongolian 
Crude Oils. Journal of the Japan Petroleum Institute, 55, 363-370.

https://www.jstage.jst.go.jp/article/jpi/55/6/55_363/_pdf

[10] Sugimoto, Y., Horie, Y., Saotome, Y., Tugsuu, T.S. and Enkhsaruul, B. (2013) Thermal Cracking of Paraffinic and Middle East Atmospheric Residues and Hydrotreatment of Distillate Products. Journal of the Japan Petroleum Institute, 56, 44-51. https://www.jstage.jst.go.jp/article/jpi/56/1/56_44/_pdf 